\title{
Factors associated with toothache among Brazilian adults: a multilevel analysis
}

\author{
Ricardo Luiz de Barreto ARANHA ${ }^{(a)}$ \\ Rafaela Silveira PINTO(b) (D) \\ Mauro Henrique Nogueira \\ Guimarães de ABREU(b) (iD) \\ Renata de Castro MARTINS(b) \\ (a) Universidade Federal de Minas Gerais - \\ UFMG, School of Dentistry, Postgraduate \\ Program in Dentistry, Belo Horizonte, Minas \\ Gerais, Brasil. \\ (b) Universidade Federal de Minas Gerais - \\ UFMG, School of Dentistry, Department of \\ Community and Preventive Dentistry, Belo \\ Horizonte, Minas Gerais, Brasil.
}

Declaration of Interests: The authors certify that they have no commercial or associative interest that represents a conflict of interest in connection with the manuscript.

\section{Corresponding Author:}

Renata Castro Martins

E-mail: r.c.martins@uol.com.br

hitps://doi.org/10.1590/1807-3107bor-2020.vol34.0036

Submitted: April 15, 2019

Accepted for publication: February 28, 2020

Last revision: March 24, 2020
Abstract: The aim of this study was to evaluate the factors associated with toothache in the adult population of Minas Gerais, Brazil. Individual data from a population sample (age 35 to 44 years) were collected from a secondary database of the SB Minas survey. Sampling was carried out by clusters and with multiple drawing stages. The eligibility criteria were to reside in areas chosen for the research, be within the age group, and accept to participate in the research. The individual variables assessed by a questionnaire and dental exams were sex, income, race/skin color, root caries, periodontal condition, need for dental treatment, and last dental appointment. The contextual variables, assessed by municipal indexes, were Human Development Index (HDI), illiteracy, unemployment, half minimum wage, quarter minimum wage, oral health team coverage, access to individual health care, and supervised tooth brushing average. The dependent variable was toothache in the past six months. A descriptive analysis was made using the Statistical Package for the Social Sciences and Hierarchical Linear and Nonlinear Modeling Software was used to perform the multilevel analyses for individual and contextual levels. An association was found between toothache and low income $(\mathrm{OR}=2.00 ; 95 \% \mathrm{CI}=1.32-3.13)$, dental caries $(\mathrm{OR}=1.86$; $95 \% \mathrm{CI}=1.22-2.86)$, periodontal condition, and living on a quarter of the minimum wage or less $(\mathrm{OR}=1.03 ; 95 \% \mathrm{CI}=1.00-1.08)$. Clinical and social factors were associated with toothache, reinforcing the need to improve public polices in oral health focused on the adult population.

Keywords: Toothache; Adult; Social Determinants of Health; Epidemiologic Factors.

\section{Introduction}

Toothache is the most prevalent acute experience in the orofacial region affecting teeth and surrounding tissues. ${ }^{1}$ In adults, toothache has been associated to mouth ulcers ${ }^{2}$ and untreated diseases as tooth decay or periodontitis. ${ }^{3,4}$ Additionally, toothache may prevent people from seeking proper dental care due to fear of pain.5,6

Epidemiological surveys show that toothache impacts people's quality of life. ${ }^{7}$ Toothache has been associated with high morbidity, psychological issues, and sleep impairment. . $2,7,7,9,1,10,11,12$ Besides that, toothache in adults 
can generate financial losses because of lost work hours and, hence, decreased productivity., 2,4,9,13,15

Several studies associate contextual and individual determinants, such as lower income, ${ }^{4,8,9,10,11,15,16,17,18,19,20}$ higher income concentration, ${ }^{20}$ low educational level, ${ }^{15,16,17,20}$ low Human Development Index, ${ }^{14,15,20}$ low levels of social capital, ${ }^{16}$ female sex, ${ }^{11,14,15,17}$ black skin color ${ }^{14,15,17}$ needing dental treatment, ${ }^{15,16}$ self-perception of health, ${ }^{16,20}$ and dental services utilization, ${ }^{16,21,22,23}$ with poor oral health status.

Toothache also has been associated with low socioeconomic status, $4,7,8,9,10,11,15,16,17,18,19,20$ oral health deterioration, ${ }^{2}$ poor dental hygiene habits ${ }^{10}$, and poor access to health services. ${ }^{14,15,16,17,18,19,20,21,22,23}$ This could be explained by the high prevalence of dental disease experienced by people in low socioeconomic groups, ${ }^{2,15,20}$ their reluctance in accessing dental services, and discredit in the efficacy of the public health system. ${ }^{7,9}$

Therefore, many determinants can influence the health-disease process, including individuals characteristics, ${ }^{2,10,15,16,17}$ factors related to living conditions $4,7,8,9,10,11,15,16,17,18,19,20$ access to health services ${ }^{16,17,18,19,20,21,22,23}$ and education, ${ }^{15,17,20}$ and socioeconomic conditions. ${ }^{15,20}$

Previous multilevel studies in adults pointed out that contextual and individual determinants are independently associated with dental pain. ${ }^{14,16}$ Contextual determinants are more strongly associated with dental pain compared to individual determinants, suggesting that the effect of social context on dental pain is more important than individual factors. ${ }^{14,16}$ However, in those studies, contextual determinants like municipal and oral health indexes were not addressed.

Historically, the socioeconomic context influences health services access. In the Brazilian society, higher use of public services has been associated with lower income, households with larger number of people including family members and non-relatives, more teeth requiring treatment, and poor health service infrastructure. Besides, black race and living in small towns (three times more than in the capital) are also associated with use of public services..$^{21,22,23}$

Treatment cost may also be a factor precluding access to dental services by economically disadvantaged people., ${ }^{719,23}$ In this way, social determinants can act as barriers to access dental services for the population even when individual social vulnerability conditions are considered. ${ }^{23}$

The evidence that health and disease are determined by social contexts is well documented. $14,15,16,20,21,23$ Despite several studies associating oral diseases

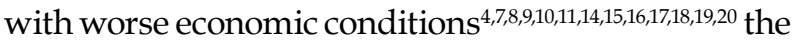
majority of studies address toothache at individual level exclusively. Multilevel studies about dental pain are rare and focused on children ${ }^{24,25}$ or adolescents. ${ }^{15,26}$ There is a gap in the literature on dental pain in the adult population adopting a multilevel approach. Therefore, it is important to evaluate health outcomes using individual and contextual determinants. There has been growing interest in public health research that considers factors defined at multiple levels, and the multilevel analysis is one of the analytical strategies that may be used as it allows inferences at the contextual and individual levels.

The identification of contextual and individual determinants of toothache in the adult population can improve equity in oral healthcare through public polices directed at this population. The aim of this cross-sectional study was to evaluate the contextual and individual determinants of toothache in the adult population of Minas Gerais, using a multilevel approach. The hypothesis tested was that toothache is associated with contextual and individual factors.

\section{Methodology}

The SB Minas was an epidemiological survey of oral health carried out in Minas Gerais state from April to December 2012 that investigated the main oral health diseases at the ages of 5 and 12 and in the age groups 15-19, 35-44 and 65-74. This cross-sectional population-based study was supported by a partnership between the Minas Gerais Department of Health (Brazilian Ministry of Health's Collaborating Center for Oral Health Surveillance) and Pontifícia Universidade Católica (PUC) of Minas Gerais. The SB Minas Gerais survey was approved by the Ethics Committee of PUC Minas (CAAE 01107412.4.0000.5137). ${ }^{3}$ 
Minas Gerais is the second most populous state in Brazil, the $3^{\text {rd }}$ wealthier state by the Gross Domestic Product (GDP) index, encompassing 853 cities, and it ranks $9^{\text {th }}$ out of the 27 states in Brazil on the Human Development Index and $8^{\text {th }}$ in the population over 16 years old in active formal employment. ${ }^{28}$

The methodology of the 2010 national survey was used as reference for the collected indices: age, draw of the municipalities, census tracts, and households and individual data. ${ }^{3}$ The sample size was also based on the severity of dental caries estimated by the DMFT index (number of teeth decayed, missing and filled), according to data from the SB Brazil 2010 for the Southeast region. For each age group and domain, the prevalence of caries and the average DMFT were used as a reference for the sample size calculation associated with an error rate. In the 35-44 age group, this error was estimated as $5 \%$. The proposed design allowed to estimate the prevalence of caries in the state of Minas Gerais, considering the age or age group. For other diseases, the representability degree varied with the estimated prevalence and severity.,21

A representative sample for the state of Minas Gerais was calculated assuring a confidence level of $95 \%$ and $80 \%$ power for the variables used in this study. ${ }^{3,21}$ Sampling ( $\mathrm{n}=61$ cities) was carried out by clusters and with multiple drawing stages. The study used three different domains: capital of state (Capital), for which data was collected from the SB Brasil 2010, and two groups of municipalities from the interior (Groups I and II) based in the "city allocation factors" used to distribute the state tax revenue for health. ${ }^{29,30}$ The Group I cluster included the more autonomous and less vulnerable cities, and Group II, the less autonomous and more vulnerable cities. Initially, 30 cities chosen by careful randomization methods were included in Group I and Group II. Eventually, 4,898 households and 4,840 inhabitants were assessed. ${ }^{3}$

For municipalities in Groups I and II, the weight was composed by the draw probability (primary sampling unit) and census tracts (secondary sampling units) draw by the proportional probability technique.

The SB Minas Gerais study used a questionnaire and dental exams to evaluate the oral health condition of the population. Sixty dentists (one per municipality) performed the clinical examinations. Data for the capital was collected from the SB Brasil. ${ }^{3}$ The dental exams were performed by trained and calibrated teams, each composed of a dentist and a notetaker. A set of dental mirror and probe was used for the task, which was performed in a well-lit environment. Minimum inter-rater reliability (Cohen's Kappa) was 0.65. The dental index followed the WHO recommendations. ${ }^{31}$ Apart from classical oral health indexes (i.e., the DMFT and CPI (community periodontal index)), questionnaires were administered by the same calibrated team throughout 2012. The questions covered sociodemographic data, socioeconomic status, dental service use, and dental treatment need.

For this study, data from adults aged 35 to 44 years old $(n=1,207)$ were extracted from the SB Minas study database. The dependent variable was presence of toothache, which was assessed with the question: "Have you had a toothache over the past six months?" The data for the independent variables was structured in two levels: individual variables (level 1) nested within contextual variables (level 2). Variables such as sex, income, race, presence of dental caries, periodontal condition, dental treatment need, last dental appointment (level 1) were extracted from the SB Minas 2012 database. Variables in level 2 were the Human Development Index ${ }^{32}$ extracted from the United Nations Development Program's section on Brazil, ${ }^{33}$ illiteracy, unemployment, earning half of the minimum wage, earning a quarter of the minimum wage extracted from the Brazilian Institute of Geography and Statistics, ${ }^{28}$ and coverage by the oral health team, access to individual dental care, and supervised tooth brushing average were extracted from the Brazilian Ministry of Health database. ${ }^{34}$ Table 1 describes each independent variable at levels 1 and 2 .

A descriptive analysis was made using the Complex Samples module of the Statistical Package for the Social Sciences (SPSS for Windows, version 22.0) to evaluate the complex sampling design of the SB Minas Gerais.

Hierarchical Linear and Nonlinear Modeling Software (HLM 6.08 statistical package) ${ }^{35}$ was used to perform the multilevel analyses. This analysis 
- Factors associated with toothache among Brazilian adults: a multilevel analysis

Table 1. Description of variables according to the level of analysis - SB Minas Gerais, Brazil, 2012.

\begin{tabular}{|c|c|c|}
\hline Level & Variable & Categories \\
\hline \multirow{21}{*}{ Level 1 - Individual } & Sex & Male and female \\
\hline & Income & Up to $R \$ 1500$ Brazilian reals* and more than $R \$ 1500$ \\
\hline & Race & $\begin{array}{l}\text { Self-reported race from the five original categories; a dichotomous variable } \\
\text { was created (white and non-white). }\end{array}$ \\
\hline & Domain & Capital group, Group I, and Group II \\
\hline & Root caries & Presence or absence \\
\hline & & Absence of disease; \\
\hline & Daridot a dition & Gingivitis/Dental calculus; \\
\hline & 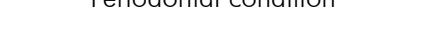 & Probing depth greater than $3 \mathrm{~mm}$; \\
\hline & & Less than two functional teeth in at least one sextant. \\
\hline & & No needs (healthy crown and root) \\
\hline & & Restoration of one surface \\
\hline & & Restorations of two or more surfaces \\
\hline & & Prosthetic crown needed for any reason \\
\hline & Treatment needs & Dental facet \\
\hline & & Pulp treatment and restoration \\
\hline & & Tooth extraction \\
\hline & & White spot treatment \\
\hline & & Sealant \\
\hline & & Less than 1 year \\
\hline & Last dental appointment & More than 1 year \\
\hline & & Never \\
\hline \multirow{8}{*}{ Level 2 - Contextual } & $\mathrm{HDI}$ & Human Development Index \\
\hline & Illiteracy & $\begin{array}{l}\text { Percentage (\%) of people who cannot read and write at least one word and } \\
\text { no language proficiency in the total resident population of an age range, } \\
\text { geographic space, and within a year }\end{array}$ \\
\hline & Unemployment & $\begin{array}{c}\text { Percentage (\%) of residents economically active, unemployed in a week, } \\
\text { geographic space, and within a year }\end{array}$ \\
\hline & Half minimum wage & $\begin{array}{l}\text { Percentage (\%) of residents with monthly revenue per capita up to half } \\
\text { minimum wage in a geographic space, within a year }\end{array}$ \\
\hline & Quarter minimum wage & $\begin{array}{c}\text { Percentage (\%) of residents with monthly per capita revenue up to a quarter } \\
\text { minimum wage in a geographic space, within a year }\end{array}$ \\
\hline & Oral Health Team Coverage & Percentage (\%) of the population covered by Oral Health Teams \\
\hline & $\begin{array}{l}\text { Access to individual dental } \\
\text { care (entrance in the scheduled } \\
\text { treatment program) }\end{array}$ & $\begin{array}{l}\text { Percentage (\%) of residents scheduled for a primary dental consultation with } \\
\text { the aim of diagnosing and elaborating a preventive/therapeutic plan to } \\
\text { address the detected needs }\end{array}$ \\
\hline & Supervised tooth brushing average & $\begin{array}{c}\text { Percentage (\%) of the population who receive inspected brushing by } \\
\text { collective actions }\end{array}$ \\
\hline
\end{tabular}

*\$1 Brazilian real $=\$ 0.5$ USD (July 2012).

assessed the association of municipal and individual variables with the absence or presence of tooth pain in the past 6 months. The multilevel analyses included 1,121 individuals from 57 municipalities and was carried out through the nonlinear logit link function, which used the fixed effects/random intercept setup. Parameters were estimated using the restricted maximum likelihood method and predictive quasi-likelihood estimation. A multilevel logistic regression model was built. In the first 
Table 2. Descriptive analysis of individual variables of adults $(n=1,207)$ from Minas Gerais, Brazil, 2012.

\begin{tabular}{|c|c|c|}
\hline Variables* & N & $\%(95 \% \mathrm{Cl})^{\dagger}$ \\
\hline \multicolumn{3}{|l|}{ Dependent variable } \\
\hline \multicolumn{3}{|l|}{ Toothache over the past 6 months } \\
\hline No & 931 & $78.9(74.7-82.5)$ \\
\hline Yes & 272 & $21.1(17.5-25.3)$ \\
\hline \multicolumn{3}{|l|}{ Independent variables (individual level) } \\
\hline \multicolumn{3}{|l|}{ Sex } \\
\hline Male & 431 & $34.9(31.4-38.5)$ \\
\hline Female & 776 & $65.1(61.5-68.6)$ \\
\hline \multicolumn{3}{|l|}{ Income } \\
\hline Up to $R \$ 1500$ & 750 & $54.6(48.3-60.8)$ \\
\hline More than R\$1500 & 438 & $45.4(39.2-51.7)$ \\
\hline \multicolumn{3}{|l|}{ Race } \\
\hline White & 482 & $44.5(40.4-48.6)$ \\
\hline Non-white & 725 & $55.5(51.4-59.6)$ \\
\hline \multicolumn{3}{|l|}{ Root caries } \\
\hline Absence & 996 & $83.3(79.9-86.3)$ \\
\hline Presence & 211 & $16.7(13.7-20.1)$ \\
\hline \multicolumn{3}{|l|}{ Periodontal condition } \\
\hline Absence of disease & 305 & $23.9(20.4-27.8)$ \\
\hline Gingivitis/dental calculus & 364 & $31.6(27.6-35.9)$ \\
\hline Probing depth greater than $3 \mathrm{~mm}$ & 173 & $15.8(12.3-19.9)$ \\
\hline Less than 2 teeth & 338 & $28.8(24.6-33.3)$ \\
\hline \multicolumn{3}{|l|}{ Treatment needs } \\
\hline No & 586 & $48.6(44.4-52.8)$ \\
\hline Yes & 621 & $51.4(47.2-55.6)$ \\
\hline \multicolumn{3}{|l|}{ Last dental appointment } \\
\hline Less than 1 year & 526 & $45.4(41.0-49.8)$ \\
\hline More than 1 year & 575 & $49.2(44.7-53.8)$ \\
\hline Never & 101 & $5.4(3.0-9.6)$ \\
\hline
\end{tabular}

"There are missing values for some variables; ‘sample design taken into account.

stage a null model estimated the basic partition of data variability between the two levels and then the individual and municipal characteristics were taken into account.

Level 1 variables were initially incorporated into the model individually before being tested combined $(p<0.05)$. Afterwards, the municipal variables (level 2) were tested, which were incorporated one by one, using the Student's $t$-test $(\mathrm{p}<0.05)$. The multilevel model was constructed with the variables that achieved a $\mathrm{p}<0.25$. Odds ratio (OR) and $95 \%$ confidence intervals $(95 \% \mathrm{CI})$ were estimated in each analysis. The reliability estimate was used to determine the adequacy of the final multilevel model. The final model included only variables with $\mathrm{p}$-value $<0.05$.

\section{Results}

Toothache in the past 6 months was reported by $21.1 \%$ of the respondents. Most participants were 
females (61.5\%), non-white (55.5\%), with income up to $\mathrm{R} \$ 1,500$ (54.6\%) (\$357 USD approximately). Several participants had gingivitis/dental calculus (31.6\%), needed dental treatment (51.4\%), had the last dental appointment within the previous year $(49.2 \%)$, and did not have dental caries (83.3\%) (Table 2). The descriptive analysis of contextual variables is shown in Table 3.

Out of 61 cities (Group I, $\mathrm{n}=30$; Group II, $\mathrm{n}=30$; Capital group =1), 3 withdrew from the original project. Additionally, data from one city (Governador Valadares) was lost, and thus excluded from the final multilevel analysis (Table 4). The null model indicated a difference in the experience of tooth pain for participants in the 57 cities assessed in this study $(\mathrm{p}<0.001)$.

The final adjusted multilevel analysis $(n=1,121)$ indicated that adults earning more than $\$ 1,500$ Brazilian reals per month had lower risk of tooth pain compared to those earning less than that amount. The missing data from $86(7.67 \%)$ individuals was due to refusal to undergo the dental exam and to respond the questionnaire. A lower income level increased the risk of toothache $(\mathrm{OR}=2.00 ; 95 \% \mathrm{CI}=1.32-3.13)$.
The presence of root caries increased the risk of toothache $(\mathrm{OR}=1.86 ; 95 \% \mathrm{CI}=1.22-2.86)$. Likewise, adults with gingivitis/dental calculus $(\mathrm{OR}=1.31$; $95 \% \mathrm{CI}=0.80-2.15)$, probing depth greater than $3 \mathrm{~mm}(\mathrm{OR}=2.05 ; 95 \% \mathrm{CI}=1.13-3.69)$ and "less than 2 functional teeth" (OR $=2.15 ; 95 \% \mathrm{CI}=1.27-3.64)$ had higher toothache risk compared to those without those periodontal conditions. Individuals with dental treatment need had 6.74-fold (95\%CI; 3.40-13.37) higher risk for tooth pain than those without. Individuals who gained up to one quarter of Brazilian minimum wage/month had $3 \%$ higher chance of oral pain $(\mathrm{OR}=1.03 ;$ 95\%CI; 1.00-1.08) (Table 5).

There was no interaction between individual income and income at the municipal level, which is a quarter of the minimum wage $(p=0.948)$ [data not shown]. In the final model, $22 \%$ of the variance in dental pain was explained by contextual variables.

\section{Discussion}

The present study assessed a set of data from a representative sample, and the associations of individual and contextual determinants with

Table 3. Descriptive analysis of contextual variables from municipalities ( $n=57)$ in Minas Gerais, Brazil, 2012.

\begin{tabular}{|c|c|c|c|c|c|c|}
\hline Variables* & p-value & Mean & $\begin{array}{l}\text { Standard } \\
\text { deviation }\end{array}$ & $\mathrm{P} 25 \%$ & P50\% & $\mathrm{P} 75 \%$ \\
\hline $\mathrm{HDI}$ & 0.200 & 0.693 & 0.062 & 0.640 & 0.697 & 0.751 \\
\hline Illiteracy & 0.000 & 11.674 & 7.891 & 5.250 & 9.100 & 16.850 \\
\hline Unemployment & 0.200 & 6.357 & 2.688 & 4.435 & 6.700 & 7.930 \\
\hline Half minimum wage & 0.063 & 38.922 & 17.459 & 21.985 & 35.780 & 55.210 \\
\hline Quarter minimum wage & 0.007 & 15.613 & 10.625 & 6.050 & 12.540 & 22.900 \\
\hline Oral health team coverage & 0.001 & 50.259 & 39.312 & 12.825 & 46.890 & 94.925 \\
\hline Access to individual dental care & 0.000 & 10.804 & 9.401 & 4.070 & 7.190 & 16.425 \\
\hline Supervised tooth brushing average & 0.000 & 3.536 & 3.829 & 0.660 & 1.820 & 5.830 \\
\hline
\end{tabular}

Values for 57 municipalities; $\mathrm{p}$-value $=$ Kolmogorov-Smirnov normality test; $\mathrm{P}=$ Percentile.

Table 4. Final estimation of variance components in the multilevel analysis (null-model).

\begin{tabular}{lccccc}
\hline Random effect & Standard deviation & Variance component & df & Chi-square & p-value \\
\hline Intercept, U0 & 0.97024 & 0.94137 & 55 & 194.49 & $<0.001$ \\
\hline
\end{tabular}


Table 5. Multilevel models (unadjusted and adjusted) for variables of individual $(n=1,1.1)$ and contextual levels associated with toothache in adults from Minas Gerais, Brazil, 2012.

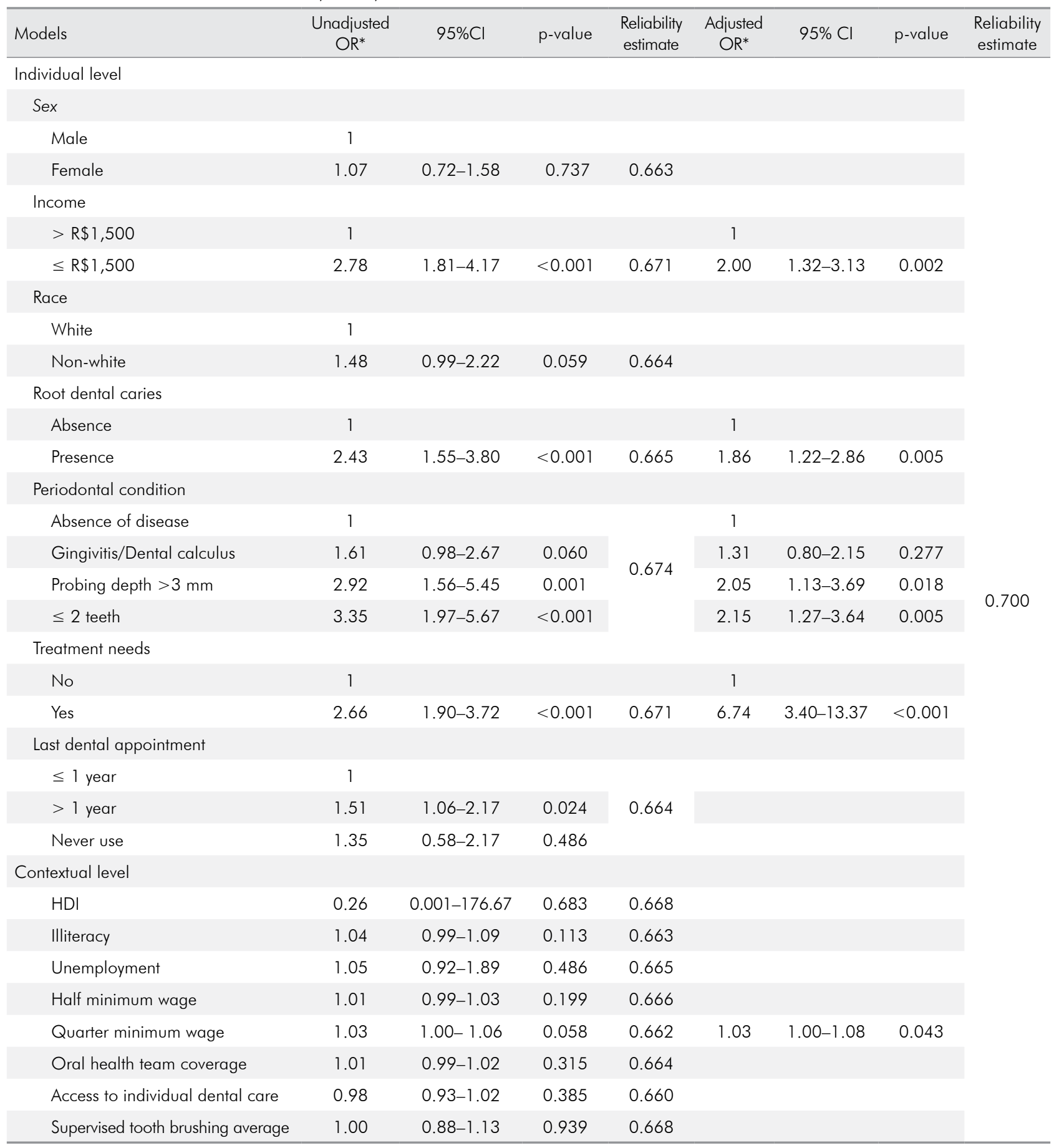

toothache among adults. The results are in accordance with others studies that associated clinical and social factors with toothache. . $^{1,7,9,12,13,14,15,16,36,37}$

It is noteworthy that $21.1 \%$ of the study population answered "yes" to having had a toothache in the past 6 months, similar to the prevalence found in a previous national study ${ }^{11}$ and higher in comparison with studies that assessed the prevalence of dental pain among adults living in Brazil's State capitals $(15.2 \%)^{14}$, and people in the United States $(14.5 \%)^{13}$ 
and South Africa (19.4\%). ${ }^{9}$ However, the rate was lower compared with a study that investigated the relationship of neighborhood and individual social capital with dental pain in adolescents, adults, and the elderly living in three cities of Paraíba, Brazil $(26.8 \%) .{ }^{16}$ Many other studies found an association between toothache and socioeconomic factors. ${ }^{2,11,15,18}$ Leung et al..$^{38}$ assessed chronic orofacial pain in a Chinese sample, including toothache enduring for at least 6 months, and found that chronic toothache was associated with low level of perceived need for treatment $(83.7 \%)$. This finding might be due to bias, since the categorization of a toothache as chronic is questionable as it is commonly connected to acute dental conditions, like acute caries.

In the current study, gender and race were not associated with toothache, although some Brazilian studies have found that toothache may be more prevalent in non-white people ${ }^{12,13,14,21}$ and others have reported that certain Asian ethnic groups either reported less orofacial pain or coped better with their pain. ${ }^{2,4,7}$ Some studies also found toothache more prevalent in women than in men., ${ }^{2,414,21}$ Women, in general, participate more in surveys and use health services more frequently than men, being submitted to more potentially painful dental procedures. ${ }^{21}$

The study found that the presence of dental caries (root caries) increased the chance of having tooth pain. Santiago et al..$^{16}$ found a higher risk of toothache in people affirming having a number of decayed teeth. Clinical periodontal condition (described as gingivitis/dental calculus, probing depth greater than $3 \mathrm{~mm}$ and less than 2 functional teeth in any sextant) were also found to be associated. Additionally, earlier epidemiological surveys have registered self-reported bleeding gums and loose teeth as associated factors. ${ }^{2}$ The effect of tooth pain on daily activities may potentially aggravate general health or precipitate oral diseases, leading to a vicious cycle. Difficulties in chewing certain foods, ${ }^{11}$ sleep disturbances ${ }^{11,13}$ uncomfortable toothbrushing, ${ }^{10}$ and difficulty cleaning teeth and gums are some of the reported effects. ${ }^{37}$

Earning less than $\mathrm{R} \$ 1,500$ at individual level increased the chance of toothache. In the literature, low income and high social vulnerability are highly associated with toothache. . $^{2,410,13,15,19,21}$ Cost has frequently been cited as a barrier for accessing better dental health services., ${ }^{7,23}$

Concerning municipal variables, earning "one quarter minimum wage" reached association independently of the income at the individual level (level 1) cited above. The decrease of one point in the income increased the chance of oral pain in adults by $3 \%$, showing the clear increased odds for toothache in poor communities. $29,11,12,13,14,15,21,37$ The time elapsed from the previous dental appointment was not associated with dental health or tooth pain in dissonance with other studies. ${ }^{13,15,16,21}$ However, patients might have had analgesics prescribed in the last dental appointment and cultural influences about pain might have been introduced, being a consequence rather than a cause of toothache. ${ }^{16}$ Other municipal level variables did not show a correlation in the final model. It is important to highlight the pathways linking contextual and individual factors and toothache. Socioeconomic inequalities restrict healthy choices in detriment of the easier ones. ${ }^{36}$ It is more difficult for poorer people to have healthy behaviors and they are exposed to a greater risk of disease that may lead to poor oral hygiene and unhealthy dietary habits. In addition, less access to fluorides and lower use of dental services of that population predispose individuals to a greater risk of more severe dental caries and dental pain. ${ }^{14,16}$ For this reason, oral diseases and toothache are more prevalent among adults with worse socioeconomic conditions. ${ }^{39}$

Although access to oral health services and oral health coverage was not included in the adjusted model, it is important to increase access and oral health coverage in the municipalities. The descriptive data shows that a large portion of the sample is probably dependent of the Brazilian public oral health system. Thus, access and oral health coverage must be improved aiming at equity in oral healthcare.

The results of the present study may be useful for practical purposes. Our findings show that clinical and social factors were associated with toothache. The results can be used to reinforce the need of providing the necessary treatment to the adult population, as well as develop public polices about prevention and oral health promotion focused at this population. 
Notwithstanding the unique and thorough multilevel analysis and the data collected from the well-calibrated SB Minas primary study, our work is limited by the cross-sectional design of both the original database and the municipal indexes, which do not allow causal inferences. Additionally, the use of a single question to collect data about toothache in the previous six months may have incorporated misclassification or memory bias. Another limitation was the lack of information about dental caries; refusals of undergoing dental exam or responding the questionnaire are expected in an epidemiological study. However, missing data was low in our study, considering that it involved a representative sample of one of the largest states in Brazil.

\section{Conclusions}

In the present study, tooth pain was associated with income, dental caries, periodontal condition, treatment need at the individual level, and living on a quarter of the minimum wage or less at the contextual level. Clinical and social factors were associated with toothache, reinforcing the need to improve equity in oral health care by public polices focused at the adult population.

\section{Acknowledgments}

This study was supported by the Pró-Reitoria de Pesquisa da Universidade Federal de Minas Gerais (PRPq/UFMG).

\section{References}

1. Estrela C, Guedes OA, Silva JA, Leles CR, Estrela CR, Pécora JD. Diagnostic and clinical factors associated with pulpal and periapical pain. Braz Dent J. 2011;22(4):306-11. https://doi.org/10.1590/S0103-64402011000400008

2. Macfarlane TV, Beasley M, Macfarlane GJ. Self-reported facial pain in UK biobank study: Prevalence and Associated Factors. J Oral Maxillofac Res. 2014 Oct;5(3):e2. https://doi.org/10.5037/jomr.2014.5302

3. Secretaria de Estado da Saúde (MG). Subsecretaria de Políticas e Ações de Saúde. Superintendência de Redes de Atenção à Saúde. SB Minas Gerais: pesquisa das condições de saúde bucal da população mineira: resultados principais. Belo Horizonte: Secretaria de Estado de Saúde, 2013 [cited 2017 Jul 14]. Available from: http://www.saude.mg.gov.br/sobre/publicacoes/estatistica-einformacao-em-saude

4. Joury E, Bernabe E, Gallagher JE, Marcenes W. Burden of orofacial pain in a socially deprived and culturally diverse area of the United Kingdom. Pain. 2018 Jul;159(7):1235-43. https://doi.org/10.1097/j.pain.0000000000001203

5. Stormon N, Pradhan A, McAuliffe A, Ford PJ. Does a facilitated pathway improve access to dental services for homeless and disadvantaged adults? Eval Program Plann. 2018 Dec;71:46-50. https://doi.org/10.1016/i.evalprogplan.2018.08.002

6. Meier ML, de Matos NM, Brügger M, Ettlin DA, Lukic N, Cheetham M, et al. Equal pain-Unequal fear response: enhanced susceptibility of tooth pain to fear conditioning. Front Hum Neurosci. 2014 Jul;8(526):526. https://doi.org/10.3389/fnhum.2014.00526

7. Goes PS, Watt RG, Hardy R, Sheiham A. Impacts of dental pain on daily activities of adolescents aged 14-15 years and their families. Acta Odontol Scand. 2008 Feb;66(1):7-12. https://doi.org/10.1080/00016350701810633

8. McGuire S, Hoogeveen J, Bacchia P, Johnstone P, Khew C, Lee B, et al. The presenting complaints of low income adults for emergency dental care: an analysis of 35,000 episodes in Victoria, Australia. Community Dent Health. 2008 Sep;25(3):143-7.

9. Ayo-Yusuf IJ, Naidoo S. Social gradient in the cost of oral pain and related dental service utilisation among South African adults. BMC Oral Health. 2016 Nov; 16(1):117. https://doi.org/10.1186/s12903-016-0313-x

10. Kakoei S, Parirokh M, Nakhaee N, Jamshidshirazi F, Rad M, Kakooei S. Prevalence of toothache and associated factors: a populationbased study in southeast iran. Iran Endod J. 2013;8(3):123-8.

11. Hafner MB, Zanatta J, Rasera Zotelli VL, Batista MJ, Sousa ML. Perception of toothache in adults from state capitals and interior cities within the Brazilian geographic regions. BMC Oral Health. 2013 Jul;13(1):35. https://doi.org/10.1186/1472-6831-13-35

12. Constante HM, Bastos JL, Peres KG, Peres MA. Socio-demographic and behavioural inequalities in the impact of dental pain among adults: a population-based study. Community Dent Oral Epidemiol. 2012 Dec;40(6):498-506. https://doi.org/10.1111/j.1600-0528.2012.00701.x

13. Vargas CM, Macek MD, Marcus SE. Sociodemographic correlates of tooth pain among adults: united states, 1989. Pain. 2000 Mar;85(1-2):87-92. https://doi.org/10.1016/S0304-3959(99)00250-X

14. Peres MA, Iser BP, Peres KG, Malta DC, Antunes JL. [Contextual and individual inequalities in dental pain prevalence among Brazilian adults and elders]. Cad Saude Publica. 2012;28 suppl:114-23. Portuguese. https://doi.org/10.1590/S0102-311X2012001300012 
- Factors associated with toothache among Brazilian adults: a multilevel analysis

15. Peres MA, Peres KG, Frias AC, Antunes JL. Contextual and individual assessment of dental pain period prevalence in adolescents: a multilevel approach. BMC Oral Health. 2010 Aug;10(1):20. https://doi.org/10.1186/1472-6831-10-20

16. Santiago BM, Valença AM, Vettore MV. Social capital and dental pain in Brazilian northeast: a multilevel cross-sectional study. BMC Oral Health. 2013 Jan;13(1):2. https://doi.org/10.1186/1472-6831-13-2

17. Kuhnen M, Peres MA, Masiero AV, Peres KG. Toothache and associated factors in Brazilian adults: a cross-sectional population-based study. BMC Oral Health. 2009 Feb;9(1):7. https://doi.org/10.1186/1472-6831-9-7

18. Bastos JL, Gigante DP, Peres KG. Toothache prevalence and associated factors: a population based study in southern Brazil. Oral Dis. 2008 May;14(4):320-6. https://doi.org/10.1111/j.1601-0825.2007.01379.x

19. Muirhead VE, Quiñonez C, Figueiredo R, Locker D. Predictors of dental care utilization among working poor Canadians. Community Dent Oral Epidemiol. 2009 Jun;37(3):199-208. https://doi.org/10.1111/j.1600-0528.2009.00471.x

20. Silva JV, Oliveira AG. Individual and contextual factors associated to the self-perception of oral health in Brazilian adults. Rev Saude Publica. 2018 Apr;52:29. https://doi.org/10.11606/S1518-8787.2018052000361

21. Pinto RS, Roncalli AG, Abreu MH, Vargas AM. Use of public oral health services by the adult population: a multilevel analysis. PLoS One. 2016 Jan;11(1):e0145149. https://doi.org/10.1371/journal.pone.0145149

22. Pinto RS, Abreu MH, Vargas AM. Comparing adult users of public and private dental services in the state of Minas Gerais, Brazil. BMC Oral Health. 2014 Aug;14(1):100. https://doi.org/10.1186/1472-6831-14-100

23. Herkrath FJ, Vettore MV, Werneck GL. Contextual and individual factors associated with dental services utilisation by Brazilian adults: A multilevel analysis. PLoS One. 2018 eb;13(2):e0192771. https://doi.org/10.1371/journal.pone.0192771

24. Ferreira-Júnior OM, Freire MC, Moreira RS, Costa LR. Contextual and individual determinants of dental pain in preschool children. Community Dent Oral Epidemiol. 2015 Aug;43(4):349-56. https://doi.org/10.1111/cdoe.12159

25. Gomes MC, Neves ET, Perazzo MF, Paiva SM, Ferreira FM, Granville-Garcia AF. Toothache and non-clinical individual and school factors in five-year- old children: multilevel analysis. Braz Dent J. 2018 Nov-Dec;29(6):569-75. https://doi.org/10.1590/0103-6440201802077

26. Freire MC, Nery NG, Jordão LM, Abreu MH. Individual and contextual determinants of dental pain in adolescents: evidence from a national survey. Oral Dis. 2019 Jul;25(5):1384-93. https://doi.org/10.1111/odi.13100

27. Diex-Roux AV. Multilevel analysis in public health research. Ann Rev Public Health. 2000;21:171-92. https://doi.org/10.1146/annurev.publhealth.21.1.171

28. Instituto Brasileiro de Geografia e Estatística - IBGE. Brasília, DF: Instituto Brasileiro de Geografia e Estátística; 2018 [cited 2018 Oct 03]. Available from: https://cidades.ibge.gov.br/brasil/mg/panorama

29. Machado EN, Fortes FB, Somarriba M. Efeitos da introdução do PAB sobre a distribuição de recursos e a prestação de serviços: o caso de Minas Gerais. Cien Saude Colet. 2004;9(1):99-111. https://doi.org/10.1590/S1413-81232004000100010

30. Malachias I, Leles FAG, Pinto MAS. Plano Diretor de Regionalização da Saúde de Minas Gerais. Belo Horizonte: Secretaria de Estado de Saúde de Minas Gerais; 2010.

31. World Health Organization. Oal health surveys: basic methods. 4th ed. Geneva: World Health Organization; 1997 [cited 2012 Jun 16]. Available from: http://www.who.int/iris/handle/10665/41905

32. United Nations Development Programme. Human Development Reports. Human developmente indicators: country profiles: Brazil. New York: United Natio Development Programme; 2018 [cited 2018 Oct 4]. Available from: http://hdr.undp.org/en/countries/profiles/BRA

33. United Nations Development Programme. Brazil. New York: United Nations Development Programme; 2018 [cited 2018 Oct 4]. Available from: http://www.br.undp.org/

34. Ministério da Saúde (BR). Departamento de Informática do SUS (DATASUS). Brasília, DF: Ministério da Saúde; 2018 [cited 2018 Oct 4]. Available from: http://tabnet.datasus.gov.br/cgi/deftohtm.exe?sim/cnv/obt10mg.def/site/http://www2.datasus.gov.br/DATASUS/index.php

35. Snidjers TAB, Bosker RJ. Multilevel analyses: An introduction to basic and advanced multilevel modeling. 2nd ed. London: Sage; 2012.

36. Watt RG, Sheiham A. Integrating the common risk factor approach into a social determinants framework. Community Dent Oral Epidemiol. 2012 Aug;40(4):289-96. https://doi.org/10.1111/j.1600-0528.2012.00680.x

37. Cavalheiro CH, Abegg C, Fontanive VN, Davoglio RS. Dental pain, use of dental services and oral healthrelated quality of life in southern Brazil. Braz Oral Res. 2016 Aug;30(1):S1806-83242016000100272. https://doi.org/10.1590/1807-3107BOR-2016.vol30.0039

38. Leung WS, McMillan AS, Wong MC. Chronic orofacial pain in southern Chinese people: experience, associated disability, and helpseeking response. J Orofac Pain. 2008;22(4):323-30.

39. Costa SM, Martins CC, Pinto MQ, Vasconcelos M, Abreu MH. Socioeconomic factors and caries in people between 19 and 60 years of age: an update of a systematic review and meta-analysis of observational studies. Int J Environ Res Public Health. 2018 Aug;15(8):E1775. https://doi.org/10.3390/ijerph15081775 